\title{
Aortic remodelling after thoracic endovascular aortic repair for acute and subacute type $B$ aortic dissection
}

\author{
Yi Zhou ${ }^{1 \#}$, Wei-Cheng Wang ${ }^{1 \#}$, Xiao-Ming Zhang ${ }^{1}$, Cui Yang ${ }^{1}$, Jing Zheng ${ }^{1}$, Lin Yang ${ }^{1}$, Ling Dong ${ }^{1}$, Xiao \\ $\mathrm{Hu}^{1}$, Tao Zhu ${ }^{2}$, Ya-Li Wang ${ }^{3}$, Yan Yang ${ }^{3}$ \\ ${ }^{1}$ Sichuan Key Laboratory of Medical Imaging, Department of Radiology, Affiliated Hospital of North Sichuan Medical College, Nanchong 637000, \\ China; ${ }^{2}$ Department of Preventive Medicine, ${ }^{3}$ Department of Cardiothoracic Surgery, Affiliated Hospital of North Sichuan Medical College, \\ Nanchong 637000, China \\ "These authors contributed equally to this work.
}

Correspondence to: Lin Yang. Sichuan Key Laboratory of Medical Imaging, Department of Radiology, Affiliated Hospital of North Sichuan Medical College, Nanchong 637000, China. Email: linyangmd@163.com.

Background: Thoracic endovascular aortic repair (TEVAR) in the current era has gained widespread acceptance as the modality of choice for the treatment of complicated aortic dissection (AD). However, reports on clinical results of TEVAR treatment of $\mathrm{AD}$ patients are mainly comparisons and analyses of results between patients in the acute and chronic phases, few reports have described the postoperative aortic remodelling of patients with subacute AD after TEVAR. The aim of this study was to investigate aortic remodelling after TEVAR in acute and subacute Stanford type B AD patients.

Methods: The clinical data of 38 Stanford type B AD patients who received TEVAR treatment in our hospital between July 2012 and December 2017 were retrospectively analysed. The maximum diameters of the aorta, the mean diameters of the true lumens (TLs) and the false lumens (FLs) of the aorta in the dissection range before and after TEVAR treatment were measured. All diameters between different groups or in the same group before and after therapy were compared using nonparametric tests. Count data were examined using the $\chi^{2}$ test.

Results: The 38 patients were $31.0-82.0$ years old with a mean age of $57.0 \pm 11.0$ years, including 31 men and 7 women, with 22 patients in the acute phase and 16 patients in the subacute phase. Among the 38 patients included in this study, 7 (18.4\%) patients had endoleaks after treatment. No perioperative deaths occurred. Analyses of computed tomography angiography measurement results showed that the baseline maximum diameters of the aorta, TLs and FLs before TEVAR between the acute and subacute groups were not significantly different $(\mathrm{P}=0.193, \mathrm{P}=0.301$ and $\mathrm{P}=0.067$, respectively). After TEVAR treatment, the maximum diameters of the aorta and the diameters of the FLs were different between the two groups $(\mathrm{P}=0.005$ and $\mathrm{P}=0.012)$, but the diameters of the TLs were not $(\mathrm{P}=0.069)$. The diameters of the TLs increased, and those of FLs decreased significantly in the acute and subacute groups after TEVAR $(\mathrm{P}<0.001, \mathrm{P}<0.001$, $\mathrm{P}<0.001$ and $\mathrm{P}=0.007$, respectively); the maximum diameters of the aorta decreased significantly in the acute group $(\mathrm{P}<0.001)$, but they did not change obviously in the subacute group $(\mathrm{P}=0.121)$.

Conclusions: TEVAR offers satisfactory results for the treatment of type B AD. Acute AD may be associated with better aortic remodelling compared to subacute AD after TEVAR.

Keywords: Aortic dissection (AD); computed tomography; Stanford type B; thoracic endovascular aortic repair (TEVAR); aortic remodelling

Submitted Feb 20, 2018. Accepted for publication May 02, 2018.

doi: $10.21037 /$ qims.2018.05.03

View this article at: http://dx.doi.org/10.21037/qims.2018.05.03 


\section{Introduction}

Aortic dissection (AD) is the most common catastrophic aortic event. The traditional treatment methods for AD mainly include medical treatment methods based on lowering the blood pressure and heart rate, analgesia, sedation and surgical intervention. Since it was first reported in 1999 (1), thoracic endovascular aortic repair (TEVAR) has gained widespread acceptance as the modality of choice for the treatment of type B AD complicated by malperfusion, ongoing growth, aortic rupture, or refractory hypertension and pain (2-5). The clinical outcome of $\mathrm{AD}$ patients after undergoing TEVAR is associated with postoperative aortic remodelling $(6,7)$. Reports on clinical results of TEVAR treatment for Stanford type B AD patients are mainly comparisons and analyses of treatment results between patients in the acute and chronic phases. Because the time span of the chronic phase is long (several weeks, months, or even years), the pathological changes and progression levels of $\mathrm{AD}$ in the chronic phase theoretically exhibit very large differences (8), resulting in inconsistent research results (9-19). Most studies have shown that postoperative complications and mortality in acute $\mathrm{AD}$ are higher than those in chronic AD (9-14). The results of some studies have shown opposite conclusions (15-17) or that stent treatment results between acute and chronic dissections were similar $(18,19)$. Therefore, developing better dissection classification systems can help clinical doctors develop treatment plans and select optimal treatment timing (20-22). A recently proposed classification method considers differences among acute, subacute, and chronic diseases, with a disease course of acute dissection of less than 2 weeks, a disease course of subacute dissection between 2 weeks and 3 months, and a disease course of chronic dissection longer than 3 months (21). However, few reports have described the clinical outcomes and postoperative aortic remodelling of patients with subacute B AD after TEVAR, and little is known about differences in postoperative aortic remodelling between the three phases of the disease. The aim of this study was to investigate morphological changes in acute and subacute $B A D$ patients after TEVAR.

\section{Methods}

\section{Patient cohort}

A total of 38 Stanford type B AD patients received TEVAR treatment in our hospital between July 2012 and December 2017. Based on the recent DISSECT classification system (21),
22 patients in this study were classified into the acute group, and 16 patients were classified into the subacute group. The preoperative baseline clinical characteristics of the patients in these two groups are shown in Table 1.

\section{Computed tomography (CT) scans}

All patients underwent CT angiography (CTA) with a 64-detector row CT scanner (Light Speed VCT; GE Healthcare, Milwaukee, WI, USA) to confirm the presence of type B AD. The scanning parameters were as follows: a tube voltage of $120 \mathrm{kV}$, tube current of $440 \mathrm{~mA}$, pitch of 0.984 , field of view (FOV) of $50 \mathrm{~cm}$, and slice thickness of $5 \mathrm{~mm}$. For all scans, the patients were positioned supine with both arms up. Each patient received an injection of $80 \mathrm{~mL}$ of anon-ionic contrast material with an iodine content of $370 \mathrm{mg} / \mathrm{mL}$ (Ultravist $370^{\circledR}$; Bayer-Schering, Berlin, Germany) at a flow rate of $5 \mathrm{~mL} / \mathrm{s}$.

\section{TEVAR procedure}

All patients received TEVAR treatment under general anaesthesia. A longitudinal incision was typically made on one side of the groin area to expose the femoral artery. The femoral artery was punctured to place a $6 \mathrm{~F}$ vascular sheath. After systemic heparinization, a gold-labelled angiographic catheter was introduced into the aorta for the whole aortic digital subtraction angiography (DSA) examination. The condition of the aortic arch and its branches, the location of tears, the anchoring area, and the blood supply of arterial branches in abdominal organs were evaluated. The anchoring area was labelled, the blood pressure was lowered to $90-100 \mathrm{mmHg}$, and a stent-graft system (Zenith TX2 Endovascular Graft, William Cook Europe ApS, Sandet 6, DK4632 Bjaeverskov, Denmark) was introduced through the femoral artery under the guidance of a stiff guide wire. After reaching the $\mathrm{AD}$ position of the thoracic aorta, the stent was released, and whole aortic imaging was repeated to evaluate the resultant conditions, such as endovascular repair of tears. The stent delivery system and sheath were withdrawn, and the incision in the femoral artery and groin was sutured. Follow-ups were performed at 1, 3, 6, and 12 months and then yearly.

\section{Data measurements}

The maximum diameters of the aorta, and the diameters of true lumens (TLs) and false lumens (FLs) in the middle 
Table 1 Clinical characteristics of the two groups in the study

\begin{tabular}{lccc}
\hline Variables & Acute group & Subacute group & P value \\
\hline Age, mean \pm SD (years) & $59.0 \pm 11.8$ & $54.2 \pm 11.1$ & 0.188 \\
Male $(\mathrm{n})$ & 20 & 11 & 0.108 \\
Hypertension (n) & 20 & 9 & 0.632 \\
Bifurcation involvement (n) & 3 & $24.0 \pm 8.3$ & 0.012 \\
Disease course, mean \pm SD (days) & $8.8 \pm 3.6$ & 1 & $<0.001$ \\
Coronary artery disease (n) & 4 & 0 & 0.466 \\
Other diseases* $(\mathrm{n})$ & 3 & 7 & 0.249 \\
Endoleak $(\mathrm{n})$ & 0 & 0.001 & \\
\hline
\end{tabular}

*, other diseases include diabetes [1], pulmonary infection [1], pleural effusion [1]. SD, standard deviation.

plane of the proximal-third, middle-third, and distal-third segments of the aorta in the dissection range before and after TEVAR treatment were measured on a CT work station. The mean diameters of TLs and FLs of the three segments were used as the diameters of TLs and FLs. The largest diameters perpendicular to the curvature of the aorta were used as the largest diameters of the aorta (short axis diameter) $(23,24)$. The distances of TLs and FLs perpendicular to the intimal flap were used as the diameters of TLs and FLs (25).

\section{Statistical analyses}

The data were analysed using SPSS 21.0 software. All diameters between the different groups or in the same group before and after therapy were compared using nonparametric test. Count data were examined using the $\chi^{2}$ test. A value of $\alpha=0.05$ indicated statistical significance.

\section{Results}

The ages of the cohort, including 31 men and 7 women, ranged from 31.0 to 82.0 years (average, $57.0 \pm 11.0$ years). Among the 38 patients included in this study, a total of 33 $(86.8 \%)$ patients had an absolute history of hypertension. Twelve (31.5\%) patients had bifurcation involvement. Five $(13.2 \%)$ patients had coronary artery disease. One (2.6\%) patient had diabetes, $1(2.6 \%)$ patient had pulmonary infection, and $1(2.6 \%)$ had pleural effusion. The mean CT scan follow-up was 13.1 months (range, 2.0-36.0 months), and $55.3 \%$ of the entire group had more than 12 months of follow-up. An average of three CT scans per patient was evaluated. Analyses of CTA measurement results showed that the baseline maximum diameters of the aorta, TLs and FLs before TEVAR between the acute and subacute group were not significantly different $(\mathrm{Z}=1.301, \mathrm{P}=0.193 ; \mathrm{Z}=1.035$, $\mathrm{P}=0.301$ and $\mathrm{Z}=1.833, \mathrm{P}=0.067$, respectively).

After TEVAR treatment, the maximum diameters of the aorta and the diameters of the FLs between the two groups were evidently different $(Z=2.809, P=0.005$ and $Z=2.514$, $\mathrm{P}=0.012$, respectively), but the diameters of the TLs were not $(\mathrm{Z}=1.818, \mathrm{P}=0.069)$ (Table 2). The diameters of the TLs increased and those of FLs decreased significantly in the acute and subacute groups after TEVAR $(Z=4.010$, $\mathrm{P}<0.001 ; \mathrm{Z}=3.516, \mathrm{P}<0.001 ; \mathrm{Z}=3.815, \mathrm{P}<0.001$ and $\mathrm{Z}=2.689$, $\mathrm{P}=0.007$, respectively); the maximum diameters of the aorta decreased significantly in the acute group $(Z=4.010$, $\mathrm{P}<0.001$ ), but they did not change obviously in the subacute group $(\mathrm{Z}=1.551, \mathrm{P}=0.121)$ (Table 3, Figure 1). Among the 38 patients included in this study, 7 (18.4\%) patients had type II endoleaks, which were treated by balloon dilatation or additional bare stent deployment. All endoleaks resolved after additional treatment. Stent-graft related complications and perioperative deaths have not occurred.

\section{Discussion}

AD results from a tear of the intimal layer, and subsequently, the blood flow enters the intimal tear, creating a flap that divides the aorta into an FL and a TL. The blood flow into the TL continuously enters the FL, increasing the pressure and continuously increasing the diameter of the FL; therefore, the TL is compressed and becomes smaller or even collapses. In the chronic phase, the persistent high pressure in the FL gradually causes aneurysmal dilatation of the aorta. The purpose of TEVAR treatment for AD 
Table 2 Comparison of diameters between the acute and subacute groups before and after TEVAR

\begin{tabular}{|c|c|c|c|c|c|c|c|c|}
\hline $\begin{array}{l}\text { Diameter } \\
(\mathrm{mm})\end{array}$ & \multicolumn{4}{|c|}{ Pre-TEVAR } & \multicolumn{4}{|c|}{ Post-TEVAR } \\
\hline Thoracic aorta & 35.6 (33.2-39.3) & 36.9 (34.1-42.0) & 1.301 & 0.193 & $26.4(25.6-30.5)$ & 35.5 (27.5-42.8) & 2.809 & 0.005 \\
\hline True lumen & $20.4(12.3-22.7)$ & $14.2(11.4-18.7)$ & 1.035 & 0.301 & 24.6 (17.9-26.2) & 19.8 (15.1-23.5) & 1.818 & 0.069 \\
\hline False lumen & $10.5(7.7-15.9)$ & 13.7 (9.7-22.4) & 1.833 & 0.067 & $1.4(0.0-8.4)$ & $12.8(7.4-19.1)$ & 2.514 & 0.012 \\
\hline
\end{tabular}

Values of diameters were expressed as median (first and third quartiles). TEVAR, thoracic endovascular aortic repair.

Table 3 Comparison of diameters before and after TEVAR in the acute and subacute groups

\begin{tabular}{|c|c|c|c|c|c|c|c|c|}
\hline Diameter (mm) & \multicolumn{4}{|c|}{ Acute group } & \multicolumn{4}{|c|}{ Subacute group } \\
\hline Thoracic aorta & 35.6 (33.2-39.3) & $26.4(25.6-30.5)$ & 4.010 & $<0.001$ & 36.9 (34.1-42.0) & $35.5(27.5-42.8)$ & 1.551 & 0.121 \\
\hline True lumen & $20.4(12.3-22.7)$ & 24.6 (17.9-26.2) & 4.010 & $<0.001$ & $14.2(11.4-18.7)$ & $19.8(15.1-23.5)$ & 3.516 & $<0.001$ \\
\hline False lumen & $10.5(7.7-15.9)$ & $1.4(0.0-8.4)$ & 3.815 & $<0.001$ & $13.7(9.7-22.4)$ & $12.8(7.4-19.1)$ & 2.689 & 0.007 \\
\hline
\end{tabular}

Values of diameters were expressed as median (first and third quartiles). TEVAR, thoracic endovascular aortic repair.
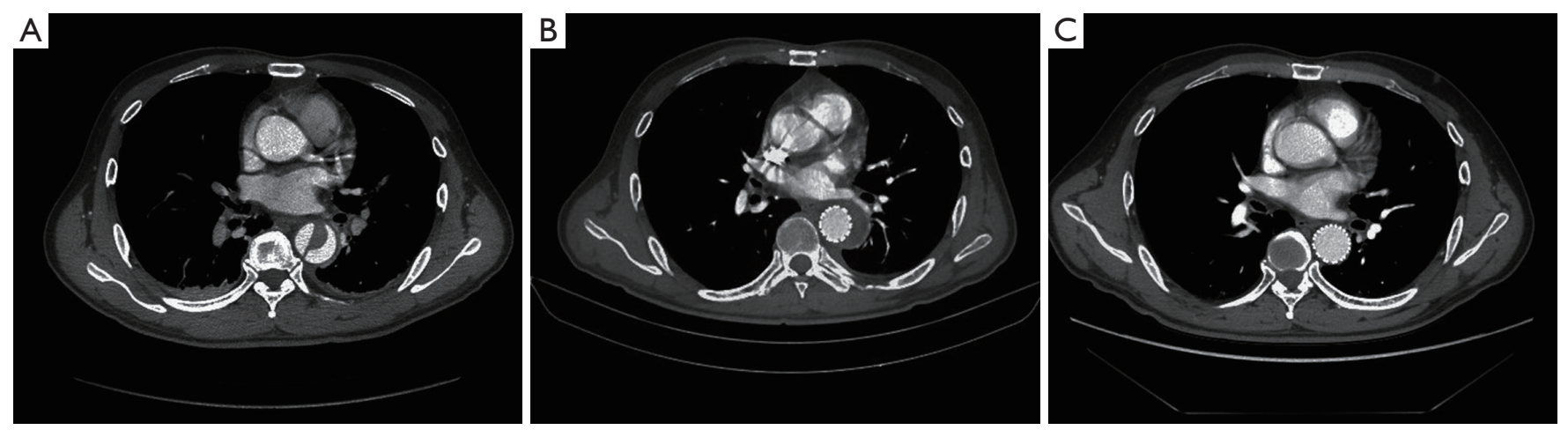

Figure 1 A 48-year-old male patient with subacute Stanford type B aortic dissection. (A) Preoperative computed tomography angiography (CTA) demonstrated the intimal flap, true lumen (TL) and false lumen (FL). The maximum diameter of the aorta and the mean diameters of the TL and FL were 38.2, 10.2 and $17.8 \mathrm{~mm}$, respectively; (B) CTA at the 1-month follow-up after thoracic endovascular aortic repair (TEVAR) displaying the stent and FL thrombus in the same patient. The maximum diameter of the aorta and the mean diameters of the TL and FL were 37.7, 22.2 and $11.7 \mathrm{~mm}$, respectively; (C) CTA at the 6-month follow-up after TEVAR exhibiting aortic remodelling as indicated by complete regression of FLs and dilation of TLs of the thoracic aorta in the same patient. The maximum diameter of the aorta and the mean diameter of the TL were 27.7 and $27.0 \mathrm{~mm}$, respectively.

is to repair the tears, isolate the FL, reduce the risk of aortic rupture, and promote aortic remodelling. The morphological changes in $\mathrm{AD}$ patients during the process of aortic remodelling after TEVAR include FL narrowing or occlusion, and TL dilation. The definitions of aortic remodelling are different across studies and include a $20 \%$ increase in the TL area, a $20 \%$ decrease in the FL area (26), and a $5-\mathrm{mm}$ decrease in the maximum diameter of the thoracic aorta $(7,15)$. In addition, one study also defined aortic remodelling as complete regression of FLs of the thoracic aorta (19).

Many researchers have reported aortic remodelling after TEVAR in patients with acute and chronic type B AD. Those studies have indicated that aortic remodelling following TEVAR is more pronounced for acute rather than chronic $\mathrm{AD}(6,26-28)$. One study (27) systematically 
analysed a total of 16 reports meeting specific inclusion criteria. The study results showed that acute dissection patients displayed a more consistent degree of remodelling compared to chronic dissection patients. Factors such as the length of aortic coverage and the timing of treatment may explain the variation observed in the chronic dissection group. Few reports have described aortic remodelling after TEVAR in patients with subacute type B AD. The VIRTUE Registry (29) describes the morphological results of TEVAR in patients with type B AD. One hundred patients with complicated acute, subacute, and chronic type $\mathrm{B} A \mathrm{D}$ were enrolled. The study showed that patients with acute and subacute $\mathrm{AD}$ exhibited greater aortic plasticity compared to patients with chronic AD. Analysis of aortic morphology revealed that patients with subacute dissection demonstrated a similar degree of aortic remodelling compared to patients with acute dissection. The rates of FL thrombosis between the three clinical groups were not significantly different in the proximal and distal descending thoracic aorta. However, an analysis of FL thrombosis rates between the diaphragm and coeliac axis revealed that patients with chronic $\mathrm{AD}$ had a significantly lower rate of FL thrombosis than patients with subacute or acute AD. The present study showed that the maximum diameter of the aorta significantly decreased in the acute group, but it did not change obviously in the subacute group after TEVAR treatment for thoracic $\mathrm{AD}$. The mean diameters of the TLs all significantly increased and those of the FLs all significantly decreased after the TEVAR procedure in the two groups. Both the maximum diameters of the aorta and the diameters of FLs in the acute group were smaller than those in the subacute group after TEVAR treatment. The results of the present study indicated that aortic remodelling following TEVAR is more pronounced in acute versus subacute $A D$, which is not consistent with the results of the VIRTUE Registry.

Aortic remodelling after TEVAR may be associated with the characteristics of the dissection (19,30-32). Type $\mathrm{B} A \mathrm{D}$ patients exhibit substantial changes over the disease course (8) that will cause different aortic remodelling patterns after TEVAR in different phases. Despite the aorta's vulnerability and fragility during the acute phase, several studies have suggested that more favourable remodelling can be observed if early interventions are attempted $(15,19)$. During the chronic phase, on the other hand, intimal flaps become more rigid and fibrotic, resulting in a reduced capacity for remodelling (19). Persistent communication between the TL and FL in the descending aorta in $\mathrm{AD}$ patients after TEVAR may cause different aortic remodelling patterns. Kim et al. (30) reported that large FL dimensions may indicate the presence of good communication between the TL and FL at the distal segment of the dissected aorta. Because TEVAR can only cover the proximal entry of the thoracic artery, some patients still have residual tears after the procedure, and the distribution and number of these residual breaches, will affect aortic remodelling. In addition, the presence of abdominal branches that are completely or incompletely connected to the FL after TEVAR may also affect aortic remodelling. Kitamura et al. (31) regarded a smaller aortic diameter and the absence of abdominal branches arising from the FL as key success factors for remodelling. In our study, 3 (13.6\%) in the acute group had branches that were completely or incompletely connected with FLs versus $9(56.3 \%)$ in the subacute group, which may be one of the reasons for inferior aortic remodelling in the subacute group compared to that in the acute group. Fanelli et al. (6) assessed the factors influencing morphological changes in acute and chronic type $\mathrm{B} A \mathrm{D}$ patients after TEVAR treatment. In their study, sixty cases of TEVAR for complicated type B acute and chronic $\mathrm{AD}$ were retrospectively reviewed. Their study showed that aortic remodelling is more prominent in acute AD patients compared to that in chronic AD patients. Aortic remodelling and clinical outcomes after TEVAR can be influenced by procedural techniques. In addition to the above factors, however, several other variables may account for differences in these outcomes.

Because the ranges of $\mathrm{AD}$ at different stages and among patients with varying severity exhibit large differences, no unified anatomical standard exists for the measurement of dissection diameters. Most studies have evaluated morphological changes in the aorta by measuring changes in the maximum diameter of the aorta and the diameters of the TLs and FLs in the dissected region at different planes. Common measurement planes include the left subclavian artery, pulmonary artery bifurcation, carina level, celiac artery level, inferior mesenteric artery, and renal artery. Studies have also measured dissection areas or volume (33-36). Measurements of diameters and areas are based on different anatomical planes of the aorta, which can easily be affected by aortic distortion and irregular crosssection shapes, resulting in measurement errors. Volume measurement can determine the overall value, which is associated with a small measurement error, but the procedure is complicated and time-consuming. Patterson et al. (36) measured diameters and areas in 100 cases of type $\mathrm{B} A D$ at 
different planes using a CT work station. Aortic TL and FL diameters and areas showed good correlations in most anatomic locations. The results in that study showed that diameter measurements using multiplanar reconstructions based on a central luminal line appear to be adequate when assessing aortic remodelling after endovascular treatment of $\mathrm{AD}$. In addition to measuring of the maximum diameters of the aorta, we also divided the patients' dissected aortas into three equal segments, and the TL and FL diameters were measured in the middle plane of the proximal-third, middlethird, and distal-third segments of the dissected region. The mean diameters of the TLs and FLs of the three segments were used as the diameters of the TLs and FLs. Using this three-segment measurement method minimised the effects of the previously mentioned anatomical factors to some extent and the complexity of volume measurement and also more comprehensively reflected aortic remodelling in the dissected aorta after interventional treatment.

In summary, the results of the present study indicated that TEVAR is an ideal method for treating type B AD. Aortic remodelling following TEVAR is more pronounced in acute versus subacute $\mathrm{AD}$ patients, which may facilitate the selection of optimal operative timing.

\section{Acknowledgements}

None.

\section{Footnote}

Conflicts of Interest: The authors have no conflicts of interest to declare.

Ethical Statement: The study was approved by Ethics Committee of Affiliated Hospital of North Sichuan Medical College (No. 2018A0220).

\section{References}

1. Dake MD, Kato N, Mitchell RS, Semba CP, Razavi MK, Shimono T, Hirano T, Takeda K, Yada I, Miller DC. Endovascular stent-graft placement for the treatment of acute aortic dissection. N Engl J Med 1999;340:1546-52.

2. Singh M, Hager E, Avgerinos E, Genovese E, Mapara $\mathrm{K}$, Makaroun M. Choosing the correct treatment for acute aortic type B dissection. J Cardiovasc Surg (Torino) 2015;56:217-29.

3. Erbel R, Aboyans V, Boileau C, Bossone E, Bartolomeo
RD, Eggebrecht H, Evangelista A, Falk V, Frank H, Gaemperli O, Grabenwöger M, Haverich A, Iung B, Manolis AJ, Meijboom F, Nienaber CA, Roffi M, Rousseau H, Sechtem U, Sirnes PA, Allmen RS, Vrints CJ; ESC Committee for Practice Guidelines. 2014 ESC Guidelines on the diagnosis and treatment of aortic diseases: Document covering acute and chronic aortic diseases of the thoracic and abdominal aorta of the adult The Task Force for the Diagnosis and Treatment of Aortic Diseases of the European Society of Cardiology (ESC). Eur Heart J 2014;35:2873-926.

4. Akin I, Kische S, Ince H, Nienaber CA. Indication, timing and results of endovascular treatment of type B dissection. Eur J Vasc Endovasc Surg 2009;37:289-96.

5. Sun $\mathrm{Z}, \mathrm{Al} \mathrm{MM}, \mathrm{Cao} \mathrm{Y}$. CT angiography in the diagnosis of cardiovascular disease: a transformation in cardiovascular CT practice. Quant Imaging Med Surg 2014;4:376-96.

6. Fanelli F, Cannavale A, O'Sullivan GJ, Gazzetti M, Cirelli C, Lucatelli P, Santoni M, Catalano C. Endovascular Repair of Acute and Chronic Aortic Type B Dissections: Main Factors Affecting Aortic Remodeling and Clinical Outcome. JACC Cardiovasc Interv 2016;9:183-91.

7. Mani K, Clough RE, Lyons OT, Bell RE, Carrell TW, Zayed HA, Waltham M, Taylor PR. Predictors of Outcome after Endovascular Repair for Chronic Type B Dissection. Eur J Vasc Endovasc Surg 2012;43:386-91.

8. Peterss S, Mansour AM, Ross JA, Vaitkeviciute I, Charilaou P, Dumfarth J, Fang H, Ziganshin BA, Rizzo JA, Adeniran AJ, Elefteriades JA. Changing Pathology of the Thoracic Aorta from Acute to Chronic Dissection: Literature Review and Insights. J Am Coll Cardiol 2016;68:1054-65.

9. Shimono T, Kato N, Yasuda F, Suzuki T, Yuasa U, Onoda K, Hirano T, Takeda K, Yada I. Transluminal stent-graft placements for the treatments of acute onset and chronic aortic dissections. Circulation 2002;106:I241-7.

10. Shimono T, Shimpo H. Transluminal stent-graft placement for the treatment of acute aortic dissection. Kyobu Geka 2006;59:674-80.

11. Jing QM, Han YL, Wang XZ, Deng J, Luan B, Jin HX, Liu XJ, Li F. Endovascular stent-grafts for acute and chronic type B aortic dissection: comparison of clinical outcomes. Chin Med J (Engl) 2008;121:2213-7.

12. Kato N, Shimono T, Hirano T, Suzuki T, Ishida $M$, Sakuma H, Yada I, Takeda K. Midterm results of stentgraft repair of acute and chronic aortic dissection with descending tear: the complication-specific approach. J Thorac Cardiovasc Surg 2002;124:306-12. 
13. Böckler D, Schumacher H, Ganten M, von TenggKobligk H, Schwarzbach M, Fink C, Kauczor HU, Bardenheuer H, Allenberg JR. Complications after endovascular repair of acute symptomatic and chronic expanding Stanford type B aortic dissections. J Thorac Cardiovasc Surg 2006;132:361-8.

14. Eggebrecht H, Herold U, Kuhnt O, Schmermund A, Bartel T, Martini S, Lind A, Naber CK, Kienbaum P, Kühl H, Peters J, Jakob H, Erbel R, Baumgart D. Endovascular stent-graft treatment of aortic dissection: determinants of post-interventional outcome. Eur Heart J 2005;26:489-97.

15. Sayer D, Bratby M, Brooks M, Loftus I, Morgan R, Thompson M. Aortic morphology following endovascular repair of acute and chronic type $\mathrm{B}$ aortic dissection: implications for management. Eur J Vasc Endovasc Surg 2008;36:522-9.

16. Chen S, Yei F, Zhou L, Luo J, Zhang J, Shan S, Tian N, Kwan TW. Endovascular stent-grafts treatment in acute aortic dissection (type B): clinical outcomes during early, late, or chronic phases. Catheter Cardiovasc Interv 2006;68:319-25.

17. Bortone AS, Schena S, D'Agostino D, Dialetto G, Paradiso V, Mannatrizio G, Fiore T, Cotrufo M, de Luca Tupputi Schinosa L. Immediate versus delayed endovascular treatment of post-traumatic aortic pseudoaneurysms and type B dissections: retrospective analysis and premises to the upcoming European trial. Circulation 2002;106:I234-40.

18. Guangqi C, Xiaoxi L, Wei C, Songqi L, Chen Y, Zilun L, Shenming W. Endovascular repair of Stanford type $B$ aortic dissection: early and mid-term outcomes of 121 cases. Eur J Vasc Endovasc Surg 2009;38:422-6.

19. Yang CP, Hsu CP, Chen WY, Chen IM, Weng CF, Chen CK, Shih CC. Aortic remodeling after endovascular repair with stainless steel-based stent graft in acute and chronic type B aortic dissection. J Vasc Surg 2012;55:1600-10.

20. HIRST AE, JOHNS VJ, KIME SW. Dissecting aneurysm of the aorta: a review of 505 cases. Medicine (Baltimore) 1958;37:217-79.

21. Dake MD, Thompson M, van Sambeek M, Vermassen F, Morales JP. DISSECT: a new mnemonic-based approach to the categorization of aortic dissection. Eur J Vasc Endovasc Surg 2013;46:175-90.

22. Steuer J, Björck M, Mayer D, Wanhainen A, Pfammatter T, Lachat M. Distinction between Acute and Chronic Type B Aortic Dissection: Is there a Sub-acute Phase? Eur J Vasc Endovasc Surg 2013;45:627-31.

23. Sueyoshi E, Sakamoto I, Hayashi K, Yamaguchi T, Imada T. Growth rate of aortic diameter in patients with type
B aortic dissection during the chronic phase. Circulation 2004;110:II256-61.

24. Manning BJ, Dias N, Manno M, Ohrlander T, Malina M, Sonesson B, Resch T, Ivancev K. Endovascular treatment of acute complicated type B dissection: morphological changes at midterm follow-up. J Endovasc Ther 2009;16:466-74.

25. Qing KX, Yiu WK, Cheng SW. A morphologic study of chronic type B aortic dissections and aneurysms after thoracic endovascular stent grafting. J Vasc Surg 2012;55:1268-75, 1275-6.

26. Watanabe Y, Shimamura K, Yoshida T, Daimon T, Shirakawa Y, Torikai K, Sakamoto T, Shijo T, Toda K, Kuratani T, Sawa Y. Aortic remodeling as a prognostic factor for late aortic events after thoracic endovascular aortic repair in type $\mathrm{B}$ aortic dissection with patent false lumen. J Endovasc Ther 2014;21:517-25.

27. Patterson BO, Cobb RJ, Karthikesalingam A, Holt PJ, Hinchliffe RJ, Loftus IM, Thompson MM. A systematic review of aortic remodeling after endovascular repair of type B aortic dissection: methods and outcomes. Ann Thorac Surg 2014;97:588-95.

28. Shi Z, Yang J, Fu W, Guo D, Xu X, Chen B, Jiang J, Yang J, Zhu T, Dong Z, Wang L, Shi Y, Tang X, Yue J. Outcomes and aortic remodelling after proximal thoracic endovascular aortic repair of post type B aortic dissection thoracic aneurysm. Vasa 2016;45:331-6.

29. VIRTUE Registry Investigators. Mid-term Outcomes and Aortic Remodelling After Thoracic Endovascular Repair for Acute, Subacute, and Chronic Aortic Dissection: The VIRTUE Registry What this paper adds. Eur J Vasc Endovasc 2014;48:363-71.

30. Kim TH, Ko YG, Kwon SW, Choi D, Lee DY, Shim WH, Hyon MS. Large false lumen area is a predictor of failed false lumen volume reduction after stent-graft repair in type B aortic dissection. J Endovasc Ther 2014;21:697-706.

31. Kitamura T, Torii S, Oka N, Horai T, Nakashima K, Itatani K, Koyama S, Hari Y, Araki H, Sato H, Miyaji K. Key success factors for thoracic endovascular aortic repair for non-acute Stanford type B aortic dissection. Eur J Cardiothorac Surg 2014;46:432-7.

32. Rodriguez-Lopez JA, Diethrich EB. Diameter or volume? The measure of success after endovascular repair of thoracic aortic dissections. J Endovasc Ther 2009;16:39-41.

33. Chemelli-Steingruber IE, Chemelli A, Strasak A, Hugl B, Hiemetzberger R, Czermak BV. Evaluation of volumetric measurements in patients with acute type B aortic dissection--thoracic endovascular aortic repair (TEVAR) 
vs conservative. J Vasc Surg 2009;49:20-8.

34. Melissano G, Bertoglio L, Rinaldi E, Civilini E, Tshomba Y, Kahlberg A, Agricola E, Chiesa R. Volume changes in aortic true and false lumen after the "PETTICOAT" procedure for type B aortic dissection. J Vasc Surg 2012;55:641-51.

35. Sobocinski J, Lombardi JV, Dias NV, Berger L, Zhou Q, Jia F, Resch T, Haulon S. Volume analysis of true and false lumens in acute complicated type B aortic dissections after thoracic endovascular aortic repair with stent grafts alone or with a composite device design. J Vasc Surg 2016;63:1216-24.

36. Patterson BO, Vidal-Diez A, Karthikesalingam A, Holt PJ, Loftus IM, Thompson MM. Comparison of aortic diameter and area after endovascular treatment of aortic dissection. Ann Thorac Surg 2015;99:95-102.

Cite this article as: Zhou Y, Wang WC, Zhang XM, Yang C, Zheng J, Yang L, Dong L, Hu X, Zhu T, Wang YL, Yang Y. Aortic remodelling after thoracic endovascular aortic repair for acute and subacute type B aortic dissection. Quant Imaging Med Surg 2018;8(4):391-398. doi: 10.21037/qims.2018.05.03 